\title{
CONCEITOS DE FILOSOFIA NA ESCOLA E NO MUNDO E A FORMAÇÃO DO FILÓSOFO SEGUNDO I. KANT
}

\author{
Marcos César Seneda* \\ mseneda@ufu.br
}

RESUMO Este texto pretende discutir, do ponto de vista kantiano, o que pode ser ensinado e o que pode ser aprendido em Filosofia. Seu objetivo é construir os argumentos hipotéticos de Kant em face do método estruturalista de leitura de textos filosóficos. Para circunscrever este tema, aparentemente muito amplo, tomaremos como fio condutor um célebre texto de aula de I. Kant, publicado por G. B. Jäsche sob o título Manual dos Cursos de Lógica Geral. Kant ministrou este curso por mais de quarenta anos, até o término de suas atividades docentes em 1797, e nele apresenta considerações bastante fecundas e atuais sobre o ensino da História da Filosofia e sobre a formação do filósofo. A partir da distinção entre conhecimento histórico e conhecimento racional, e da distinção entre o conceito de filosofia na escola e o conceito de filosofia no mundo (AK 9:24), procuraremos apresentar as contribuições kantianas que podem ainda ser consideradas pertinentes para se discutir o modo de ensinar Filosofia e a formação do filósofo.

Palavras-chave Conceito de Filosofia na escola; Conceito de Filosofia no mundo; Ensino de Filosofia; História da Filosofia; Método estruturalista.

ABSTRACT This text intends to discuss, from the Kantian point of view, what may be taught and what may be learned in Philosophy. Its objective

\footnotetext{
* Professor Adjunto do Departamento de Filosofia (FAFCS) da Universidade Federal de Uberlândia. Artigo recebido em 16 set. 2008 e aprovado em 18 maio 2009.
}

KRITERION, Belo Horizonte, nº 119, Jun./2009, p. 233-249. 
is to construct Kant's hypothetical arguments in face of the structuralist method of reading philosophical texts. To circumscribe this theme, which is apparently quite broad, we take as guide line a well-known classroom text from I. Kant, published by G.B. Jäsche under the title Manual of General Logic Courses (Manual dos Cursos de Lógica Geral). Kant taught for more than forty years, until the end of his teaching activities in 1797, and on it he presents considerations which are quite fertile and current regarding the teaching of the History of Philosophy and the formation of the philosopher. Based on the distinction between historical knowledge and rational knowledge, and the distinction between the concept of philosophy in the school and the concept of philosophy in the world (AK 9:24), we will try to present Kantian contributions which may still be considered relevant to discuss the way of teaching Philosophy and the formation of the philosopher.

Keywords Concept of Philosophy in the school; Concept of Philosophy in the world; Teaching of Philosophy; History of Philosophy; Structuralist method.

\section{Um problema posto a partir do modo de interlocução da disciplina}

O modo como Kant define a Filosofia pelo uso ${ }^{1}$ que se faz da própria razão rompe com o valor lógico e histórico que pode, por critério metodológico, ser atribuído aos sistemas filosóficos. Poderia, portanto, o filósofo do sistema ter sido, a um só tempo, um antiestruturalista e um anti-historicista? ${ }^{2}$

Para se pôr como objeto de exame a definição da Filosofia, ou seja, para se examinar a questão sobre o modo de filosofar e, consequentemente, sobre a formação do filósofo, é forçoso também se examinar o quadro em que pode ser aceita a resposta a esta questão. Uma resposta dada no início do século XXI jamais poderá desconsiderar o método de estudo que dominou todo o século XX. Trata-se do método estrutural de leitura, do qual temos uma formulação clara no texto "Tempo histórico e tempo lógico na interpretação dos sistemas

1 Na Lógica de Jäsche, Kant comenta a dificuldade de se determinar "[...] onde cessa o uso do intelecto comum e começa o do intelecto especulativo [...]", e afirma que "por essa determinação da diferença entre uso comum da razão e seu uso especulativo (zwischen gemeinem und speculativem Vernunftgebrauche) é possível decidir a partir de que povo se deve datar o início do filosofar" (AK 9:27). A Filosofia principia, portanto, com um certo uso da razão. Ou seja, Kant reporta esta questão ao ânimo (das Gemüt), isto é, a partir dos usos possíveis do ânimo, podemos encontrar os fundamentos possíveis das tarefas cognitivas e de seus respectivos objetos.

2 Como o método estrutural de leitura de textos filosóficos demarca uma posição clara em face do historicismo, torna-se então forçosa e fecunda a contraposição destas duas posições. 


\section{filosóficos", apresentado por V. Goldschmidt no XI Congresso Internacional de Filosofia (Bruxelas, 1953). ${ }^{3}$ \\ Para retratá-lo, retomemos as palavras do próprio autor:}

De um modo mais geral, repor os sistemas num tempo lógico é compreender sua independência, relativa talvez, mas essencial, em relação aos outros tempos em que as pesquisas genéticas os encadeiam. A história dos fatos econômicos e políticos, a história das ciências, a história das idéias gerais (que são as de ninguém) fornecem um quadro cômodo, talvez indispensável, em todo o caso, não filosófico, para a exposição das filosofias; eis aí, escreve E. Bréhier, "o tempo exterior ao sistema". - A biografia, sob todas as suas formas, supõe um tempo vivido e, em última instância, não filosófico, porque é o autor da biografia, não o autor do sistema, que comanda seu desenrolar-se; mas o sistema, qualquer que seja seu condicionamento, é uma promoção, como diz M. Guéroult, a propósito de Fichte: "Bem se pode (pois) transpor na ordem do especulativo o que se passou na alma do filósofo", seguindo-se o caminho inverso, impõe-se ao sistema uma desqualificação. (GOLDSCHMIDT, 1963, p. 144-145)

Ao opor tempo histórico e tempo lógico, autor da biografia e autor do sistema, o não filosófico e o filosófico, V. Goldschmidt reporta-nos a uma dimensão estritamente estrutural, como se o tempo encerrado em uma obra fosse essencialmente lógico, ou seja, como se ele dependesse exclusivamente do seu desdobramento conceitual. ${ }^{4}$

Haveria como a filosofia de Kant atender às exigências propostas por V. Goldschmidt? ${ }^{5} \mathrm{Na}$ abertura dos Prolegômenos, Kant afirma:

3 Trata-se do texto "Temps historique et temps logique dans l'interpretation des Systèmes philosophiques", Actes du Xle Congrès International de Philosophie, t. XII, 1953. Foi traduzido por leda e Oswaldo Porchat Pereira e inserido como apêndice de A religião de Platão, também de Victor Goldschmidt, publicado pela Difel em 1963.

4 É preciso se ponderar o fato - neste momento que é de crítica e reavaliação das conquistas de um métodochave de leitura - de que a tradição filosófica francesa tem clara noção dos limites do estruturalismo, reconhecendo que seu emprego pode vir a ser frutífero ou não em vista dos objetos com que ele se depara. No Prefácio ao estudo introdutório da tradução do texto "Que é orientar-se no pensamento?", de Kant, que A. Philonenko preparou para a Vrin, F. Alquié observa: "M. Philonenko, sabendo que o texto de Kant apenas podia ser compreendido quando exatamente recolocado em seu contexto histórico, reconstituiu esse contexto com a maior precisão" (2001, p. 10). O próprio Philonenko confirma esse procedimento, defendendo-o em face de um comentário linear do texto de Kant, que poderia não apresentar maiores ganhos do que uma paráfrase. Em vista dos temas e polêmicas que recortam esse texto, esclarece: "[...] nós decidimos escolher por quadro geral de nossas análises a 'marcha das coisas', porque ela nos permitirá - ao menos nós o esperamos - integrar em um todo orgânico a multidão de elementos do texto kantiano, sem, no entanto, apresentar uma simples reprodução deste" (2001, p. 32). Com "a marcha das coisas", A. Philonenko reporta-se ao histórico das contraposições que deram origem à polêmica. De qualquer modo, trata-se de uma discussão no âmbito do método estrutural, na medida em que o objeto de disputa continua a ser o modo de ler e esclarecer as dificuldades de um texto filosófico.

5 A relevância desta questão pode ser medida pelo testemunho do próprio O. Porchat, quando, em relação a este texto, pondera: "Consideramos essa comunicação, juntamente com o artigo de Martial Guéroult sobre 'Le problème de la légitimité de l'histoire de la philosophie' [...], como os dois momentos mais altos da metodologia científica em história da filosofia" $(1963$, p. 6). O. Porchat considera que este método permite alcançar uma real objetividade, "[...] que consiste na reconstituição explícita do movimento do 
Há eruditos para quem a História da Filosofia (tanto a antiga quanto a nova) é sua própria filosofia, os presentes prolegômenos não são escritos em vista deles. Eles precisam esperar até que aqueles que se esforçaram por haurir das fontes da própria razão (aus den Quellen der Vernunft) tenham concluído sua tarefa, e então será a sua vez de dar ao mundo notícia do acontecido. (1983b, 5:A 3 - grifo nosso)

Kant aqui indica a possibilidade de se disjungir Filosofia e História da Filosofia. Essa disjunção contraria frontalmente o tratamento que estamos hoje habituados a conceder à disciplina, pois arrima-se na tese de que o significativo para a Filosofia não se encontra na história da disciplina, mas nos usos possíveis da razão que as ciências tornaram efetivos. Esta observação também pode lançar luz sobre o procedimento adotado em outros textos de Kant, na medida em que, do ponto de vista teórico, ocorre uma persistente redefinição do espaço de interlocução da Filosofia. Para Kant, a Filosofia não deve mais se ater aos sucessivos sistemas filosóficos, considerados como acervos exemplares e genuínos dos seus objetos, mas tem de se dirigir às ciências, que devem doravante se tornar os seus interlocutores privilegiados.

\section{A gradação entre o histórico e o racional}

Esta passagem dos Prolegômenos evidencia não só a pouca consideração com os historiadores da própria filosofia, mas põe em relevo, ainda, a distinção entre fonte histórica e fonte da própria razão. Esta distinção, Kant a extrai de Wolff. ${ }^{6}$ Este assimila, assim como o faz Kant, o histórico ao empírico (ÉCOLE, 1990, p. 66-68). O histórico, portanto, recebe uma acepção mais ampla do que a que herdamos de Heródoto, que vincula o histórico ao testemunho. Pois, particularmente em Wolff e também em Kant, o histórico constitui-se de data, que podem originar-se seja da observação, seja da experimentação,

pensamento do autor, refazendo seus mesmos caminhos de argumentação e descoberta, segundo seus diversos níveis, respeitando todas as suas articulações estruturais, reescrevendo, por assim dizer, segundo a ordem das razões, a sua obra, sem nada ajuntar, entretanto, que o filósofo não pudesse e devesse assumir explicitamente como seu" (1963, p. 7). O texto de O. Porchat consegue ser, a um só tempo, sucinto e emblemático, retratando não os principais passos, mas o próprio modo de mover-se do método estrutural de leitura. Que o autor tenha posteriormente mudado radicalmente de postura e tenha publicamente se posicionado contra o método estruturalista, trata-se de assunto para outra reflexão.

6 Segundo Caygill (2000, p. 171), "no conceito de Kant, a história pode ser dividida em duas grandes subespécies, a primeira indicando uma forma de saber, a segunda um padrão de informação sobre os eventos da história natural e humana". É basicamente a esta segunda espécie de história à qual Kant se refere na Lógica de Jäsche ao definir o conhecimento "histórico" como ex datis. Kant, portanto, não quer tratar do conhecimento datado, mas do conhecimento produzido através de dados. Assim, conquanto contenha o narrativo, o histórico designa todo o conhecimento que se acumula ou se adquire através de dados. Esta distinção, embora aparentemente simples, é fundamental em Kant, pois possibilita uma outra chave de leitura para entender, do ponto de vista do aprendizado, a separação entre o empírico e o puro. 
seja do testemunho. Assim, repercutindo o ensinamento de Wolff, Kant opõe o histórico ao racional. ${ }^{7} \mathrm{O}$ conhecimento histórico seria constituído a partir de dados, e o conhecimento racional, a partir de princípios. Na Lógica de Jäsche, Kant apresenta a seguinte classificação: "segundo sua origem objetiva [...]", isto é, segundo suas fontes, "[...] todos os conhecimentos são ou racionais ou empíricos; segundo sua origem subjetiva [...]", isto é, segundo o modo de sua aquisição ou aprendizado, “[...] os conhecimentos são ou racionais ou históricos [...]" (AK 9:22).

Este esquema, produzido a partir de Wolff, permite a Kant pensar a relação entre fonte (objetiva) e aprendizado (subjetivo). Assim, por um lado, segundo sua origem objetiva, um conhecimento terá uma fonte empírica, se extrair seus objetos da sensibilidade (como a biologia ou a náutica), ou terá uma fonte racional, caso possa produzir seus objetos a partir da elaboração de notas ou da construção de conceitos (como a própria Filosofia e a Matemática) (AK 9:22). Por outro lado, segundo o modo de seu aprendizado, um conhecimento será racional, se puder ser aprendido a partir de princípios, ou histórico, se tiver de ser aprendido a partir de dados (AK 9:22). A oposição entre o racional e o histórico, no entanto, não é concebida radicalmente, mas de forma graduada, uma vez que todas as ciências dependem, em maior ou menor grau, dos dois tipos de conhecimentos. A Matemática, por exemplo, poderia ser aprendida maximamente a partir de princípios, a Geografia não poderia ser aprendida sem um acervo abrangente de dados, a Engenharia, por sua vez, dependeria da junção constante de conhecimentos a partir de princípios e a partir de dados. Conquanto aparentemente simples, este esquema permite a Kant pensar a gradação entre o histórico e o racional, ${ }^{8}$ porque, ao definir o histórico como o conhecimento a partir de dados, Kant tem a possibilidade de afirmar que, na medida em que o racional é também transformado em dados - o que sempre pode ocorrer do ponto de vista do aprendizado — torna-se ele também histórico. ${ }^{9}$

7 Na Lógica, Kant primeiramente faz a distinção entre os conhecimentos históricos e os racionais (AK 9:22). Na sequência, a partir da definição de conhecimentos racionais, faz a distinção entre conhecimento filosófico e matemático (AK 9:23). Embora Kant defina de maneira própria a distinção entre os conhecimentos filosófico e matemático, os componentes desta distinção, no entanto, remontam a Wolff, que no Discurso preliminar sobre a filosofia em geral dedica um capítulo inteiro, ou seja, 28 parágrafos, à distinção que pode ser estabelecida entre os conhecimentos histórico, filosófico e matemático (WOLFF, 2006, p. 6988).

8 Esta gradação também já está pressuposta em Wolff (2006, p. 78-79), quando afirma que quem possui o conhecimento dos dados acerca da órbita de um planeta, mas não consegue operar com o princípio que possibilita o seu cálculo, "[...] tem um conhecimento histórico do conhecimento matemático de Newton relativamente ao movimento dos planetas".

9 Kant cita o exemplo (AK 9:22) do marinheiro e do juiz, e julga inclusive a conveniência de se conhecer algo somente historicamente ou também a partir de seus fundamentos racionais. Assim, o marinheiro poderia 
A gradação entre o histórico e o racional, como pressuposta por Kant, traz — para nossa perplexidade — consequências antiestruturalistas. Kant afirma: "a partir da mencionada diferença entre conhecimentos objetivamente racionais e subjetivamente racionais, fica claro também que, sob certa consideração, se possa aprender Filosofia sem poder filosofar (dass man Philosophie ... lernen könne, ohne philosophieren zu können)" (AK 9:22). Poderíamos nos perguntar, socraticamente, se alguém pode aprender uma arte sem estar apto para exercê-la. Para enfrentarmos esta questão, a reflexão Kant-Wolff torna-se muito útil, pois ela possibilita pensar uma arte a partir de um dúplice modo de aprendizado: o que se faz a partir de dados e o que se produz a partir de princípios. Além disso, ela possibilita pensar a conversão entre o racional e o histórico, uma vez que qualquer saber pode ser convertido em um conjunto de dados e pode, portanto, tornar-se objeto de aprendizado. Assim, podemos aprender Filosofia seja a partir dos usos da própria razão (a partir de princípios), seja a partir dos sistemas que se sucederam historicamente (a partir de dados). Kant sustenta, no entanto, que quem aprendeu Filosofia apenas historicamente de fato adquiriu um saber, do qual pode fazer uso mecânico, sem, contudo, estar apto para exercê-lo integralmente. O aprendizado da Filosofia, portanto, se dá em dois níveis, e, em consequência disso, alguém pode ter apreendido um sistema filosófico e, ainda assim, permanecer sem filosofar.

A outra questão, que decorre paralelamente desta, poderia ser formulada do seguinte modo: que pode ser ensinado em Filosofia? Esta questão, paradoxalmente, não recobre a questão do que pode ser aprendido. Quanto a esta última, notemos tratar-se de duas questões:

I) aprender Filosofia através dos sistemas filosóficos;

II) e aprender a filosofar por meio do uso da própria razão.

Do ponto de vista do aprendizado, portanto, uma pessoa pode aprender as duas coisas. Já do ponto de vista do ensino, pode-se:

I) ensinar Filosofia através dos sistemas filosóficos;

II) mas não se pode ensinar a filosofar, pois isto implica fazer uso autonomamente da própria razão.

A autonomia, por seu fundamento, pode ser objeto de aprendizado, na medida em que a razão se ocupa de si própria, mas esta ocupação não pode ser objeto de ensino, porque é essencialmente prática. Na Lógica de Jäsche, Kant afirma: "ninguém que não seja capaz de filosofar pode intitular-se filósofo.

conhecer as tabelas de navegação somente historicamente, ou seja, como um conjunto de dados, que isto lhe seria suficiente. Mas o juiz, por sua vez, se somente dominasse o código como um conjunto de procedimentos, seria totalmente inapto para a sua função. 
Mas só se aprende a filosofar pelo exercício que fazemos por nós mesmos da razão (durch Übung und selbsteigenen Gebrauch der Vernunft)" (AK 9:25). E inquire:

como a Filosofia poderia propriamente ser aprendida, se em Filosofia cada pensador edifica a sua obra, por assim dizer, sobre as ruínas de uma outra e nenhuma jamais alcançou um estado de permanência em todas as suas partes? Por isso, por seu fundamento, a Filosofia não pode ser aprendida, porque ela ainda não está dada. (AK 9:25)

Do ponto de vista histórico, Kant constata a falta de permanência dos sistemas, que se sucedem sem se complementar. O objetivo, portanto, não é nem demolir os sistemas já construídos nem edificar outro sistema filosófico por sobre as ruínas dos anteriores. Kant constata radicalmente: "a Filosofia ainda não está dada", ou seja, não há Filosofia. Ao contrário das outras ciências, que encontraram um caminho seguro (método) para seus conhecimentos e alcançaram assim permanência, a Filosofia sempre recomeçou, deixando em suas ruínas as marcas desta falta de fundamento.

A Crítica da razão pura é um livro sobre este caminho seguro, ou seja, sobre o método científico. Nela, Kant não faz uma teoria a partir da História da Filosofia, mas a partir da história do método da ciência ocidental, que localiza em dois pontos: a geometria euclidiana e a física newtoniana. Cada um destes dois pontos, Kant designa como uma revolução no modo de pensar; ${ }^{10}$ revolução não social, mas empreendida por um determinado uso da razão; revolução, sobretudo, pela qual a Filosofia ainda não havia passado.

É a partir destes dois pontos, da geometria euclidiana e da física newtoniana, que Kant propõe a investigação da principal questão e fio condutor da Crítica da razão pura: como são possíveis os juízos sintéticos a priori? Kant conscientemente interrompe o diálogo com os sistemas filosóficos, para, de um ponto de vista externo, interrogar a Filosofia a partir de ciências dadas e constituídas. Notemos, portanto, que a Filosofia não é inquirida de dentro, ou seja, a partir de sua própria história, mas de fora, isto é, a partir dos usos da razão que ciências já consolidadas tornaram possíveis. ${ }^{11}$ Uma prova cabal

10 Para demarcar o ingresso da matemática e da física na via segura da ciência, Kant utiliza basicamente a mesma expressão, revolução do modo de pensar (Revolution der/ihrer Denkart - KrV BXI e BXIII), indicando que estas ciências haviam descoberto um modo de proceder que a metafísica ainda desconhecia (KrV $\mathrm{BXVI)}$.

11 O modo básico de relação de Kant com a História da Filosofia é, assim, a desconfiança. Que não nos assuste, por conseguinte, o fato de, na Lógica, no "Breve esboço de uma História da Filosofia" (AK 9:2733), Kant dedicar apenas um parágrafo a toda a Filosofia Medieval. Vimos acima a observação polêmica de Kant nos Prolegômenos, de que "há eruditos para quem a História da Filosofia (tanto a antiga quanto 
disso está presente no próprio texto da Lógica, em que, além da distinção entre o conhecimento histórico e o racional, e entre o conhecimento a partir de dados e a partir de princípios, Kant também introduz a distinção entre o conhecimento por conceitos e o conhecimento por construção de conceitos, com vistas a separar radicalmente a Filosofia e a Matemática (AK 9:23). Kant inquire a Filosofia, portanto, a partir da Física e da Geometria. É por meio das construções destas ciências que ouvimos a voz de Kant, perguntando à Metafísica em que se fundamenta seu poder de síntese para que tenha acesso ao domínio dos conhecimentos teóricos.

\section{A formação do filósofo a partir dos conceitos de Filosofia na escola e no mundo}

Uma vez que a filosofia crítica é pensada a partir dessa revolução no modo de pensar levada a cabo pela Física e pela Matemática, há que se perguntar, por conseguinte, se o histórico da constituição do sistema kantiano tem implicações para se responder à questão do que pode ser aprendido e ensinado em Filosofia. Na Lógica (AK 9:23-26), Kant considera a formação filosófica sob um duplo aspecto: segundo o seu conceito na escola (nach dem Schulbegriffe) e segundo o seu conceito no mundo (nach dem Weltbegriffe — in sensu cósmico) (AK 9:24).

Segundo seu conceito na escola, Kant afirma que a Filosofia é uma "doutrina da habilidade" e que o filósofo, assim preparado, é um "técnico da razão", capaz de construir regras para empregá-las em fins quaisquer (AK 9:24). Por esta definição, podemos então dizer que Kant concebe a Filosofia de um ponto de vista aristotélico, a saber: ela seria uma ciência que dispõe todas as outras ciências em uma cadeia de fins, com vistas, por meio deste expediente, a pensar os fins últimos da razão. A principal habilidade do filósofo seria, por conseguinte, a de converter fins em meios, para poder subordiná-los e unificá-los sob outros fins. Desse ponto de vista, a Filosofia apresenta dois componentes: "em primeiro lugar, um acervo suficiente de conhecimentos racionais; em segundo lugar, um nexo sistemático desses conhecimentos ou sua ligação na Ideia de um todo" (AK 9:24). Assim, enquanto habilidade, ou seja, enquanto cultivo do modo de se fazer uma coisa, a Filosofia pode ser designada por uma competência técnica, composta por um acervo de

a nova) é sua própria filosofia" (1983b, 5:A 3 - grifo nosso), a qual indica uma redefinição do espaço de interlocução da Filosofia. Desse modo, as principais questões postas para a filosofia crítica no âmbito teórico não advêm mais do estudo dos outros sistemas filosóficos, mas da interlocução com a matemática e a física, entendidas como ciências que nos ensinaram usos universais e válidos do intelecto. 
conhecimentos racionais e por um modo de empregá-los para pensar fins quaisquer, os quais têm de poder assumir o formato do que Kant designa uma arquitetônica. Nesse sentido, percebemos que Kant concebe a formação escolar do filósofo a partir de uma engenharia, que o capacita a converter fins quaisquer em meios que possibilitem, numa estrutura arquitetônica, pensar a meta final da razão. Logo, enquanto aquisição de uma habilidade, há uma parte técnica da formação filosófica que pode e deve ser ensinada. Uma das principais características dessa habilidade seria o cultivo rigoroso e técnico de uma terminologia, que capacitasse o filósofo a reordenar os conhecimentos de ciência no interior de uma arquitetônica.

Toda a obra do período crítico retrata isto fielmente. Tomemos alguns dados objetivos. O período crítico se inicia com a publicação da Crítica da razão pura, em 1781. A dificuldade de leitura desta e das obras que se seguiram estava centrada, possivelmente, não só na novidade das questões propostas, mas também no uso metódico, rigoroso e preciso da terminologia. ${ }^{12}$ A preocupação de assim proceder está retratada lapidarmente na seguinte observação da Lógica: "exatidão de fórmulas de conformidade com um fim é rigor (eine zweckmässige Genauigkeit in Formalien ist Gründlichkeit) (uma perfeição pela escola, uma perfeição de escola)" (AK 9:47). É notável como Kant conjuga o rigor terminológico com a tarefa cognitiva a que ele se destina. E este modo de proceder — herdado possivelmente das recomendações de Wolff $^{13}$ — pode ser detectado em toda a obra do período crítico. Nesta fase de sua reflexão, os mesmos conceitos sempre cumprem a mesma tarefa cognitiva e progressivamente adquirem determinações a partir dos problemas cuja

12 Esta preocupação está presente inclusive na correspondência. Podemos observá-la explicitamente em uma carta a Marcus Herz, de 24 de novembro de 1776, onde Kant pontua: "uma Crítica, uma ciência estritamente formulada [...] requer mesmo para sua fundamentação expressões técnicas de todo suas" (AK 10:199 - apud F. CASTILHO, 1998, p. XVI).

13 Embora em obra de caráter e objetivos bastante distintos, Wolff também faz uso de terminologia rigorosa e inteiramente articulada. As recomendações de Kant em KrV B369, relativas ao uso da terminologia, repercutem claramente os ensinamentos de Wolff (2006), que, no Discurso preliminar sobre a Filosofia em geral, dedica a este problema um capítulo inteiro, o quinto, intitulado "Do estilo filosófico". Este, no entanto, não encerra nenhuma preocupação literária, mas prescreve o uso claro, rigoroso e articulado da terminologia. Wolff recomenda que a) o filósofo evite se distanciar das acepções que os vocábulos têm no uso comum da linguagem $(2006, \S 142)$; b) contudo, alerta que se deve atribuir a mesma significação ao mesmo vocábulo (2006, §143); c) e que se deve manter fixa e determinada a significação de um vocábulo (2006, §144); d) para que, de forma similar ao modo matemático, os mesmos vocábulos mantenham-se como veículos das mesmas consequências no decorrer da argumentação, com o fim de obter que "as proposições anteriores entrem nas demonstrações das posteriores" (2006, §143); por fim, f) quanto aos vocábulos que devem ter um significado particular no interior da própria disciplina, Wolff os denomina "termos filosóficos" (2006, §146); e g) alerta que se deve evitar neologismos, substituindo para cada um dos termos, na medida do possível, a definição então herdada por uma outra definição que seja mais própria ao uso que agora se lhe queira atribuir, preservando assim o emprego dos mesmos termos (2006, $\S 147)$. 
solução tornam possível. A primeira crítica já aparece com uma terminologia rigorosamente definida pelo autor. Disso advém a dificuldade de sua primeira leitura, uma vez que, no confronto com o autor, o leitor terá de conciliar sua compreensão de termos já rigorosamente definidos com o procedimento da obra de, paulatinamente, expor a determinação desses termos a partir das tarefas cognitivas que eles desempenham no seu interior.

Só isto explicaria o fato de este desconhecido professor de Königsberg ter sido dicionarizado ainda em vida e em tão curto período de tempo. Nada menos do que cinco dicionários acompanharam a publicação da obra crítica do autor. ${ }^{14}$ É quase inevitável então que nos perguntemos: a força heurística da obra crítica não repousaria também na força e rigor da terminologia empregada? Ou seja, a capacidade de empreendimento de uma nova abordagem não decorreria, paradoxalmente, da própria formação — no sentido aqui apontado - escolástica do autor? A formulação de uma terminologia rigorosa e orientada para a execução de tarefas cognitivas poderia ser um traço importantíssimo para distinguir a obra do período crítico da obra do período pré-crítico, uma vez que esta já contém problemas decisivos, mas tratados de maneira pontual e desconexa, enquanto aquela, pelo expediente de uma terminologia, possibilita que esses problemas sejam construídos a partir da articulação de tarefas cognitivas que, como numa partitura, ora se opõem, ora se superpõem, ora se intercomunicam a partir de distintos domínios.

No emprego desse acervo de conhecimentos racionais, para converter fins em meios e subordiná-los entre si, encontramos, possivelmente, o Kant tributário da História da Filosofia. Não só leitor de Platão, Aristóteles, Cícero, Leibniz e Hume, mas também frequentador dos compêndios de Metafísica e Ética de Baumgarten e do compêndio de Lógica de Meier. ${ }^{15}$ Mas que História

14 É preciso dar a devida atenção ao esforço precoce de lexicografia que acompanha a recepção da obra crítica de Kant. Em menos de duas décadas, essa obra terá sua terminologia transposta para cinco dicionários de época, alguns com vários volumes, que pretendem apreender a disposição sistemática dos escritos kantianos em uma ordenação alfabética. Isto se torna patente a partir de um retrato sumário do registro de N. Hinske (1996, p. X-XI), que elenca os seguintes dicionários: Samuel Heinicke, Wörterbuch zur Kritik der reinen Vernunft und zu den philosophischen Schriften von Herrn Kant, Pressburg, 1788; Karl Heinrich Heydenreich, Propaedeutick der Moralphilosophie nach Grundsätzen der reinen Vernunft, Leipzig, 1794; George Samuel Albert Mellin, Encyclopädisches Wörterbuch der kritischen Philosophie [...], Züllichau u. Leipzig/Jena u. Leipzig, 1797-1804; Johann Christian Lossius, Neues philosophisches allgemeines RealLexikon oder [...], Erfurt, 1803; Carl Christian Erhard Schmid, Wörterbuch zum leichtern Gebrauch der Kantischen Schriften, Jena, 1798 (este último teve quatro edições ampliadas uma após a outra no decorrer de doze anos, sendo sua primeira edição, ainda bastante simplificada, de 1786).

15 Os manuais certamente tiveram influência decisiva no modo como Kant formou sua reflexão sobre o ensino e o aprendizado da Filosofia. No quadro da universidade prussiana, em que se insere a atividade docente de Kant, não há a liberdade de cátedra, traço distintivo da universidade moderna obtido mediante a conjunção do ensino e da pesquisa. F. Castilho define lapidarmente a essência dessa universidade, ao afirmar que, nela, "o aprendizado resulta do ensinado" (1998, p. XII), ou seja, decorre da frequentação 
da Filosofia aparece na obra kantiana? Por certo que não a dos sistemas filosóficos, mas uma história do uso da razão, na qual a própria Filosofia não é um agente relevante e nem desempenha papel destacado. Qual a relação, então, entre o ato de filosofar e a História da Filosofia? Kant indica: "quem queira aprender a filosofar deve considerar, ao contrário, todos os sistemas da Filosofia apenas como História do Uso da Razão e como objeto do exercício do próprio talento filosófico" (AK 9:26). Fica clara, na exposição kantiana, a concepção da História da Filosofia como um acervo de conhecimentos racionais, cujo valor não se encerra nos sistemas de que se originou, mas é inerente aos problemas para os quais ele possibilita encontrar solução.

Mas a Filosofia não pode ser pensada somente a partir do seu conceito na escola, porque envolve um dúplice ponto de vista. Assim, do ponto de vista cosmopolítico, a Filosofia torna-se uma "doutrina da sabedoria", e o filósofo assume o ofício não de um mero técnico, mas de um "legislador da razão", que deve utilizar sua habilidade de pensar meios para fins quaisquer com o objetivo de relacionar os diversos usos da razão com "a meta final da razão humana" (AK 9:24). Assim considerada, segundo o seu conceito no mundo, a Filosofia deve então nos conduzir ao

[...] fim supremo a que todos os outros fins se subordinam e no qual todos devem se unificar.

O campo da Filosofia, nesta significação cosmopolítica, pode reduzir-se às seguintes questões:

1) que posso saber?

2) que devo fazer?

3) que me é permitido esperar?

4) que é o homem?

A Metafísica responde à primeira questão; a Moral, à segunda; a Religião, à terceira; e a Antropologia à quarta. (AK 9:24-25)

Estas questões envolvem o ato de filosofar. A primeira pode ser investigada a partir de um uso condicionado do intelecto, uma vez que eu posso investigar

de algum compêndio ou manual, uma vez que o ensino não tem correlação precípua com a pesquisa. Assim, por força de portaria ministerial, o docente tinha de adotar um compêndio para a sequência de seus cursos, cujo uso era obrigatório. Kant pautar-se-á por dois autores, ambos wolffianos: Alexander Gottlieb Baumgarten (1714-1762) e George Friedrich Meier (1718-1777). "De Baumgarten", informa F. Castilho, "adota três tratados: um para o curso de Metafísica (Metaphysica, 1757, em latim) e dois para o de Ética (Ethica philosophica, 1740, 1751, e Initia philosophiae practicae primae, 1760, também em latim). De Meier, discípulo de Baumgarten, para o curso de Lógica Geral adota o Extrato da Doutrina da Razão (Auszug aus der Vernunftlehre, 1752), um resumo da volumosa Doutrina da Razão" (F. CASTILHO, 1998, p. XIII). O esforço de Kant de separar dois conceitos de Filosofia, na escola e no mundo, decorre por certo de uma reflexão sobre sua condição concreta como docente, em que o ensino escolar ameaçava reduzir a Filosofia a uma disciplina simplesmente propedêutica ao aprendizado das demais profissões, estas sim, no contexto prussiano, detentoras de uma clara significação no mundo. 
a possibilidade do conhecimento científico a partir de seu êxito empírico. ${ }^{16} \mathrm{~A}$ segunda e a terceira só podem ser objeto de um uso próprio e autônomo da razão, pois elas adquirem sentido a partir de uma legislação que o homem põe para si mesmo. A quarta, segundo Kant, seria o ponto de convergência das outras três, que devem ser pensadas no quadro de referência da Antropologia.

As três questões assim formuladas, culminando na questão antropológica, revelam o esforço antiestrutural de Kant para retirar a filosofia da escola e situála no mundo como extensão cosmopolítica. Mas como operar essa passagem incomensurável da escola ao mundo? Ela somente é factível na medida em que o mundo assume essa dimensão cosmopolítica. Mas como se estende perante o homem essa dimensão cosmopolítica? Essa dimensão apenas será desdobrada na medida em que o homem efetivar sua humanidade, "[...] fazendo-se não somente cidadão, mas cidadão do mundo" (GOYARD-FABRE, 1997, p. 93). Trata-se de uma destinação, portanto, que não pode ser alcançada no nível do indivíduo, mas somente no nível da espécie, e cujo veículo não deve ser a moralidade, mas o direito administrado em escala universal. ${ }^{17}$ Essa destinação pressupõe a junção entre o histórico e o arquetípico, uma vez que a história e a liberdade, projetadas na ideia de progresso, podem tornar-se pensáveis a partir do homem situado em uma perspectiva cosmopolítica. Assim, a perspectiva do homem isolado pensado como um sujeito de direitos é ainda insuficiente para pensar a destinação humana. "Diferentemente do burguês (Stadtbürger)," nos diz Goyard-Fabre, "atento antes de tudo a seus interesses privados, o cidadão (Staatsbürger), em sua civilidade que o vota a serviço do Estado, é já animado por um querer do universal" (1997, p. 94). Mas este querer,

16 Conquanto a primeira questão (teórica) seja menos importante do que as outras três (de cunho prático), não se pode ignorar, por um lado, que o procedimento kantiano está fundado no intercâmbio epistêmico com as ciências empíricas, e, por outro, que esse procedimento jamais torna as ciências empíricas um fundamento positivo do uso prático da razão. V. Rohden descreve de modo fecundo essa relação quando afirma que "[...] a Filosofia como sabedoria - no sentido de referência de todos os fins ao fim último da razão humana - é possível somente com a ajuda da ciência. Este ponto de vista também hoje válido, de uma filosofia mediada pela ciência (no que diz respeito aos meios de realização do projeto filosófico), pode ao mesmo tempo servir também como um corretivo à atual orientação das ciências, que concebem a si mesmas dogmaticamente, isto é, acriticamente, como fim ou como próprio fundamento. São por isso péssima filosofia, e assim mesmo não sabem que elas estão orientadas apenas tecnologicamente à satisfação de necessidades e interesses infundados" (1981, p. 56). Pondo as ciências empíricas no quadro da meta final da razão, V. Rohden consegue explicitar o quão periculoso seria permitir que elas se concebessem como fins em si próprias. Uma vez que estas ciências definem-se tecnologicamente, ou seja, pela construção de meios em vista de fins condicionados quaisquer, elas jamais podem ser tomadas como guias seguros dos interesses práticos da razão.

$17 \mathrm{Na}$ quinta proposição do texto sobre a ideia de uma história universal, de 1784, Kant afirma: "O maior problema para a espécie humana, a cuja solução a natureza a obriga, é alcançar uma sociedade civil que administre universalmente o direito" (KANT, 1986, p. 14). Notemos, portanto, a vinculação forte que começa a ser estabelecida na reflexão de Kant entre o conceito de filosofia no mundo e a unificação da história empírica humana que passa a ser projetada na esfera do direito. 
projetado na esfera do direito, não pode ser pensado como uma dimensão pura prática, pois se estende de maneira infinita na tarefa sempre inacabada de pensar arquitetonicamente a posição do homem no mundo.

Por isso a Filosofia, segundo o seu conceito no mundo (nach dem Weltbegriffe), somente pode ser compreendida a partir de sua significação cosmopolítica (in dieser weltbürgerlichen Bedeutung) (AK 9:24-25). Consequentemente, em sua significação última (in der letztern Bedeutung) (AK 9:24) a Filosofia não está dada, porque a posição do homem no mundo é sempre uma posição a partir do mundo. Se tomarmos por base a Antropologia, perceberemos que a dimensão cosmopolítica do homem, ou seja, a que define o homem como cidadão do mundo, não pode ser separada do conhecimento histórico. A Antropologia, situada no extremo do período crítico, ${ }^{18}$ permite uma invasão do histórico, seja como dado empírico, ou como observação, ou como testemunho. Kant, por conseguinte, atribuirá grande valor à capacidade de transformar o histórico em racional, ou seja, de subsumir a vida aos fins da razão, pois se trata de uma capacidade fundamental para situar o homem como ser no mundo e para responder à questão sobre que é o homem.

Por outro lado, se considerarmos a possibilidade de converter o racional em histórico, transformando-o em dados a serem aprendidos, a Filosofia apresenta uma radical diferença em relação a todas as outras ciências. O seu conhecimento histórico-subjetivo sempre se apresenta destituído de valor, pois, sempre que um sistema filosófico é convertido em dados para poder ser apreendido subjetivamente, ele se desvincula do conceito de filosofia no mundo. Por isso Kant pressupõe que o aprendizado da Filosofia seja antiestrutural: ele não deve preparar aquele que se instrui para que possa ingressar em um sistema filosófico, mas deve transformar toda a história do uso da razão em meios que possibilitem a construção de soluções para a filosofia a partir de seu conceito no mundo, ou seja, para a compreensão do homem como "sua própria meta final" (KANT, 1983a, 10:BA III).

18 R. Terra faz uma importante observação sobre o fato de que os textos da Lógica e da Antropologia não se comunicam diretamente. Nesse sentido, afirma: "É preciso dizer, entretanto, que a Antropologia de 1798 não responde à questão que é posta na Lógica. Articular a teoria, a prática, a finalidade natural e Deus em torno da questão - que é o homem? — é algo que escapa à Antropologia; nós aí já nos deparamos com um movimento de totalização do pensamento kantiano que apenas vem a ocorrer mais tarde. Este movimento, nós o encontraremos indicado na Lógica e, também, sempre retomado no Opus postumum, onde ele se desenvolve como um tipo de esforço contínuo" (1997, p. 164). Portanto, a articulação entre a questão cosmopolítica e a antropologia, como posta na Lógica, tem de forçosamente ser reconstruída a partir de vários textos em que Kant se ocupa - nas palavras de R. Terra (1997) - de uma ontologia do presente, pondo sob exame, por exemplo, ora a noção de esclarecimento, ora a função do filósofo e da universidade, ora os fins da história e do direito. 


\section{Conclusão: a História da Filosofia e o caráter dzetético do ato de filosofar}

Retornemos então à questão que abriu estas considerações: seria o filósofo do sistema um antiestruturalista?

Se tivermos em mente a leitura de Kant da obra de Hume, por exemplo, torna-se evidente que Kant recupera vários traços estruturais do texto humeano. Por outro lado, de um ponto de vista externo à obra, Kant aponta incisivamente o que localiza como deficiência ou contradição. No entanto, é patente a desconsideração de Kant pela História da Filosofia tomada enquanto conjunto de sistemas, que encerrariam um valor interno a partir da ordem das razões que os estruturam. Acresce-se a isto, ainda, uma visão nitidamente instrumental da História da Filosofia. Kant a trata como um acervo de conhecimentos racionais, que devem ser unificados por usos próprios da disciplina. É isto o que Kant designa como o que pode ser ensinado em Filosofia: este instrumental que conforma uma competência técnica, uma habilidade a ser adquirida. ${ }^{19}$ Mas o fim desta habilidade não se conjuga com a validade interna dos sistemas filosóficos, ela se subordina ao ato de filosofar. Quando alguém filosofa, submete esta habilidade a um fundamento que lhe é próprio, e complementa, assim, sua formação, conjugando o que pode ser ensinado com o que pode ser autonomamente aprendido.

Por isso afirmamos que a gradação entre o histórico e o racional, como pressuposta por Kant e Wolff, traz consequências antiestruturalistas. Como Kant identifica o histórico não somente com construções biográficas, psicológicas ou sociológicas, mas com o conhecimento obtido a partir de dados, disso resulta, paradoxalmente, uma inversão de perspectivas: onde o estruturalismo pensa ter descoberto o filosófico e eliminado o histórico, Kant justamente encontrará um conjunto de dados (do ponto de vista objetivo) que pode ser adquirido historicamente (do ponto de vista subjetivo). A gradação entre o histórico e o racional possibilita, portanto, converter a leitura estrutural

19 Kant afirma que "duas coisas principais caracterizam propriamente um filósofo: 1) a cultura do talento e da habilidade para a empregar numa diversidade de fins, 2) a perícia no uso de todos os meios para fins quaisquer". E salienta: "ambas devem estar unidas, pois sem conhecimento jamais alguém se tornará um filósofo [...]" (AK 9:25). Notemos, por um lado, que se Kant entende que a Filosofia somente se efetiva quando consegue subordinar fins quaisquer aos fins supremos da razão, jamais considera, por outro lado, desimportante a formação de escola, pois é esta base técnica que possibilitará o acesso ao propriamente filosófico. Trata-se de grave equívoco, portanto, entender a proposição de que se pode "[...] aprender Filosofia sem poder filosofar" (AK 9:22) a partir do pressuposto de que a formação de escola poderia ser suprimida ou bastante abreviada em benefício da significação cosmopolítica do conceito de Filosofia. Conquanto jamais realize por si só a tarefa da Filosofia, a formação de escola permanece a base do procedimento filosófico. 
da História da Filosofia em um método de escola — nas palavras de Kant - que jamais se ocupa do conceito de filosofia no mundo.

A formulação kantiana, portanto, põe fortemente em evidência um aspecto que o estruturalismo elide. Em Kant, o conceito da filosofia na escola tem sempre de estar subordinado ao conceito de filosofia no mundo. A Schulphilosophie será sempre a posição do homem que não está no mundo, ou seja, que não adquiriu a cidadania de se orientar por ideias cosmopolíticas. Ele conhece os meios, mas desconhece os fins últimos. Por isso ele se dispersa, se realiza passivamente, de modo privativo, porque nunca põe para si a meta final que subordina todos os meios. Assim, por um lado, o estruturalismo remete a obra de volta à escola, encerrando o seu valor de verdade em sua consistência interna; por outro, jamais a incomoda com a questão que Kant nomeia cosmopolítica.

Retornemos agora à segunda questão, posta no início deste texto: seria o filósofo do sistema um anti-historicista?

Por um lado, Kant parece sê-lo, uma vez que parte da tarefa a ser empreendida pela Filosofia parece ter sido subtraída ao tempo histórico. Kant reconhece que não haveria filosofia transcendental sem Euclides e Newton, os quais mostraram possíveis usos da razão que estenderam a capacidade de representação do homem a objetos universais. Conquanto este fato, por si, já indique a presença mínima e incontornável de uma historicidade, Kant considera a geometria euclidiana e a física newtoniana como revoluções no método de pensar, ou seja, Kant não considera essas ciências como resultado de determinações históricas significativas, mas como empreendimentos do intelecto que tornaram possível o conhecimento transcendental. Por outro lado, Kant parece reconhecer o lócus histórico de sua reflexão, uma vez que não somente reivindica sua Filosofia como crítica, mas afirma que sua época é "a época da crítica" (das Zeitalter der Kritik - AK 9:33). A história, no entanto, nunca se caracteriza em Kant pelas determinações com as quais os fatos históricos, em suas múltiplas dimensões (econômicas, sociais, políticas, etc.), transportam-se para o interior do percurso do pensamento. Ao invés de atentar-se à cronologia dos fatos, à possível inteligibilidade de suas sequências, Kant ocupa-se com o que poderia ser considerado o fundamento semântico da história do pensamento, ou seja, com o que denomina a história dos usos possíveis do intelecto e da razão.

Por isso, quando Kant afirma que "[...] por seu fundamento a Filosofia não pode ser aprendida, porque ainda não há Filosofia" (AK 9:25), ou quando afirma que a Filosofia é ciência da "teleologia da razão humana (teleologia rationis humanae)" (KrV, B867), tornando-se o filósofo o "legislador da razão 
humana" $(\mathrm{KrV}, \mathrm{B} 867)$, ele a retira do tempo cronológico para fundamentalmente situá-la no diálogo com as ciências e em conformidade com os usos da razão que se tornam concebíveis a partir deste diálogo. Ou seja, se esta ciência existe é porque os fins desta razão têm de ser objeto de constante reexame e de investigação continuada. Esta é a paradoxal resposta kantiana: a Filosofia existe porque a razão humana sempre se pergunta por seu télos, mas, enquanto conhecimento, ao contrário das outras ciências, a Filosofia não está dada. Eis a força da sua atualidade!

\section{Referências}

ALQUIÉ, Ferdinand. Préface. In: KANT, Immanuel. Qu'est-ce que s'orienter dans la pensée?. Tradução e notas de Alexis Philonenko. Paris: Vrin, 2001. p. 7-13.

CASTILHO, Fausto. Apresentação. In: KANT, Immanuel. Manual dos cursos de lógica geral. Edição bilíngüe; tradução e apresentação de Fausto Castilho. Campinas: IFCH-Unicamp; Uberlândia: EDUFU, 1998. p. XI-XIX.

CAYGILL, Howard. Dicionário Kant. Tradução de Álvaro Cabral. Rio de Janeiro: Jorge Zahar, 2000.

ÉCOLE, Jean. La métaphysique de Christian Wolff. Hildesheim: Georg Olms, 1990. $2 \mathrm{Bd}$.

GOLDSCHMIDT, Victor. Tempo histórico e tempo lógico na interpretação dos sistemas filosóficos. In: . A religião de Platão. Tradução de Ieda e Oswaldo Porchat Pereira. São Paulo: Difusão Européia do Livro, 1963. p. 139-147.

GOYARD-FABRE, Simone. L' homme et le citoyen dans l' anthropologie kantienne. In: FERRARI, Jean. L'année 1798: Kant et la naissance de l'anthropologie au siècle des lumières. Paris: Vrin, 1997. p. 81-97. Actes du Colloque de Dijon. 9/11 maio 1996.

HINSKE, Norbert. Einleitung. In: Wörterbuch zum leichtern Gebrauch der Kantischen Schriften. Darmstadt: Wissenschaftlich Buchgesellschaft, 1996. p. VII-XXXII.

KANT, Immanuel. Anthropologie du point de vue pragmatique. Tradução de Michel Foucault. Paris: Vrin, 1994.

KANT, Immanuel. Anthropologie in pragmatischer Hinsicht. In: . Werke in zehn Bänden. 5. Aufl. Hrsg. von Wilhelm Weischedel. Darmstadt: Wissenschaftliche Buchgesellschaft, 1983a. Bd. 10.

KANT, Immanuel. Crítica da razão pura. Tradução de Valerio Rohden e Udo Baldur Moosburger. 3. ed. São Paulo: Nova Cultural, 1987.

KANT, Immanuel. Idéia de uma história universal de um ponto de vista cosmopolita. Edição bilíngüe, organizada por Ricardo Terra e traduzida por Ricardo Terra e Rodrigo Naves. São Paulo: Brasiliense, 1986. p. 9-41.

KANT, Immanuel. Kritik der reinen Vernunft. Nach der 1. und 2. Orig.-Ausg. Hrsg. von Raymond Schmidt. 3. Aufl. Hamburg: Meiner, 1990. 
KANT, Immanuel. Manual dos cursos de lógica geral. Tradução e apresentação de Fausto Castilho. Edição bilíngüe. Campinas: IFCH-UNICAMP; Uberlândia: EDUFU, 1998. [Foi aqui utilizada a seguinte edição de referência: KANT, Immanuel. Logik, ein Handbuch zu Vorlesungen. Bd. 9., S. 11-150. In: Kant's Gesammelte Schriften. Hrsg. von der Königlich Preussischen Akademie der Wissenschaften. Berlin und Leipzig: W. de Gruyter, 1923.

KANT, Immanuel. Prolegomena zu einer jeden künftigen Metaphysik die als Wissenschaft wird auftreten können. In: . Werke in zehn Bänden. 5. Aufl. Hrsg. von Wilhelm Weischedel. Darmstadt: Wissenschaftliche Buchgesellschaft, 1983b. Bd. 5.

KANT, Immanuel. Prolegómenos a toda a metafísica futura que queira apresentar-se como ciência. Lisboa: Edições 70, 1987.

PHILONENKO, Aléxis. Introduction. In: KANT, Immanuel. Qu'est-ce que s'orienter dans la pensée?. Tradução e notas de A. Philonenko. Paris: Vrin, 2001. p. 15-82. PORCHAT PEREIRA, Oswaldo. Prefácio introdutório. In: GOLDSCHMIDT, Victor. A religião de Platão. Tradução de Ieda e Oswaldo Porchat Pereira. São Paulo: Difusão Européia do Livro, 1963. p. 5-10.

ROHDEN, Valerio. Interesse da razão e liberdade. São Paulo: Ática, 1981.

TERRA, Ricardo Ribeiro. Foucault lecteur de Kant: de l'antropologie à l'ontologie du présent. In: FERRARI, Jean. L'année 1798: Kant et la naissance de l'anthropologie au siècle des lumières. Paris: Vrin, 1997. p. 81-97. Actes du Colloque de Dijon. 9/11 maio 1996. p. 159-171.

WOLFF, Christian. Discours préliminaire sur la philosophie en general. Paris: Vrin, 2006. 